\title{
El fenómeno del reclutamiento de niños, niñas y adolescentes por grupos armados organizados ilegales - caso Colombia-
}

The phenomenon of the recruitment of children and adolescents by illegal organized armed groups

- case of Colombia -

Autor: Víctor Hugo Mendoza Tovar

DOI: https://doi.org/10.19053/16923936.v19.n37.2021.13012

Para citar este artículo:

Mendoza Tovar, V.(2021). El fenómeno del reclutamiento de niños, niñas y adolescentes por grupos armados organizados ilegales - caso Colombia -.

Derecho y Realidad | ISSN Impreso 1692-3936 | ISSN En línea 2619-5607

Vol. 19 - Número 37 | Enero - Junio de 2021 | pp. 127 - 141 DOI: https://doi.org/10.19053/16923936.v19.n37.2021.13012
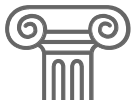


\section{El fenómeno del reclutamiento de niños, niñas y adolescentes por grupos armados organizados ilegales -caso Colombia-}

The phenomenon of the recruitment of children and adolescents by illegal organized armed groups - case of Colombia -

\section{Víctor Hugo Mendoza Tovar}

Especialista en Seguridad Informática de la Universidad INPAHU. MBA en Administración y Dirección de empresas de la Universidad Camilo José Cela, España. Magister en Derechos Humanos y Derecho Internacional Humanitario de los Conflictos Armados de la Escuela Superior de Guerra, Colombia. Doctor en Gerencia y Política Educativa de la Universidad de Baja California, México. Administrador de sistemas e informática, Universidad Santo Tomás de Aquino

vhmendoza@gmail.com

Recepción: Marzo 2 de 2021

Aceptación: Mayo 3 de 2021

\section{RESUMEN}

El presente ensayo muestra de manera sucinta las dinámicas derivadas del conflicto interno armado en Colombia y el valor estratégico de la economía ilegal donde cada día se incrementa el número de niños, niñas y adolescentes (NNA) que son utilizados por grupos armados al margen de la ley para trabajos propios de inteligencia, remesas, servidumbre sexual, fabricación e instalación de minas antipersonales, entre otras. El Tratado de Paz firmado en 2016 por el Estado colombiano y la guerrilla de las FARC, permitió una reducción en el reclutamiento de NNA; sin embargo, el aumento de las disidencias de las ex-FARC y los Grupos Armados Organizados (GAO) que hacen presencia en el territorio nacional, han vuelto a utilizar el reclutamiento como política interna para ensanchar las filas de combatientes y su accionar delictivo aun cuando el Derecho Internacional Humanitario (DIH), la jurisprudencia nacional e internacional lo prohíben.

\footnotetext{
* Este documento es producto del proyecto de investigación para optar el título de Doctor en Gerencia y Política Educativa de la Universidad de Baja California.
} 
La metodología empleada en esta investigación académica es descriptiva con enfoque cualitativo, en el cual se enuncia la normatividad y jurisprudencia internacional enmarcada en el Derecho Internacional Humanitario de los conflictos armados y la declaración Universal de los Derechos Humanos, pretendiendo realizar una radiografía sobre el fenómeno del reclutamiento de NNA en Colombia, siendo este un documento insumo de consulta en el estudio y consecución de investigaciones de índole social, donde se abordan fenómenos sociales.

\section{PALABRAS CLAVES}

Reclutamiento de Niños; Niñas y Adolescentes (NNA); Derecho Internacional Humanitario; Comité Internacional Cruz Roja (CICR); Mutación de la guerrilla en Colombia; Conflicto interno armado colombiano; guerra de guerrillas en Colombia; Grupos Armados Organizados (GAO).

\section{ABSTRACT}

This essay succinctly shows the dynamics derived from the internal armed conflict in Colombia and the strategic value of the illegal economy where the number of children and adolescents (children and adolescents) who are used by illegal armed groups for intelligence work, remittances, sexual servitude, manufacture and installation of anti-personnel mines, among others, is increasing every day. The Peace Treaty signed in 2016 by the Colombian State and the FARC guerrilla allowed for a reduction in the recruitment of children and adolescents; however, the increase in the number of ex-FARC dissidents and Organised Armed Groups (GAO) present in the national territory, have once again used recruitment as an internal policy to expand the ranks of combatants and their criminal activities, even though International Humanitarian Law (IHL) and national and international jurisprudence prohibit it.

The methodology used in this academic research is descriptive with a qualitative approach, in which the regulations and international jurisprudence framed in the
International Humanitarian Law of armed conflicts and the Universal Declaration of Human Rights are enunciated, aiming to make an x-ray on the phenomenon of recruitment of children and adolescents in Colombia, being this document an input document for consultation in the study and achievement of research of a social nature, where social phenomena are addressed.

\section{KEYWORDS}

Recruitment of Boys; Girls and Adolescents (NNA); International Humanitarian Law; International Red Cross Committee (ICRC); Mutation of the guerrillas in Colombia; Colombian armed conflict; guerrilla warfare in Colombia; Organized Armed Groups (GAO).

\section{INTRODUCCIÓN}

En la historia de la humanidad, en algunas ocasiones, se vio la utilización directa o el desempeño activo de menores de edad en funciones de combate, por ejemplo los "enfants de troupe" en el ejército napoleónico (1798-1815), "los voluntarios adolescentes de la Guerra Civil de los Estados Unidos (1861-1865)" (Cardoza, 2002), o la movilización desesperada de las "juventudes hitlerianas $(\mathrm{HJ})$ en Alemania en la última etapa de la Segunda Guerra Mundial (1945)", (Kater, 2002), pero eso fueron más bien excepciones. Por lo general, se ha observado una norma no escrita contra el uso de menores en la guerra.. Las razones no fueron principalmente morales, sino prácticas: los menores de edad normalmente no fueron capaces de soportar las exigencias físicas del combate.

Según el libro "Historical Development and Legal Basis", de la autora Mary Ellen O'Connell, con el auge del derecho internacional humanitario, que surgió desde la segunda mitad del Siglo XIX, no parecía necesario prohibir el reclutamiento de menores. El crimen de la utilización de niños soldados, es decir, "reclutar o alistar a niños menores de quince años en las fuerzas o grupos armados o utilizarlos para participar activamente en las hostilidades" (Estatuto de Roma 1998), es una adición relativamente 
reciente al corpus de crímenes de guerra. La razón por la incorporación de este crimen es la creciente proliferación de niños soldados en los conflictos contemporáneos. "La multiplicación de armas baratas y ligeras que pueden ser llevadas y utilizadas por estos ha llevado a un gran aumento en el uso de niños soldados que se ven como baratos, maleables y dispensables. Hoy en día, cientos de miles de niños son utilizados como soldados en los conflictos armados a nivel mundial" (United Nations, 1996). Muchos niños son secuestrados, reclutados y sometidos a todo tipo de actos inhumanos; y al tiempo, otros menores se unen a las organizaciones armadas para salir de la pobreza u obligados por el contexto violento u opresivo en el que se encuentran; (...) "la determinación de un menor de incorporarse a un grupo armado no es libre indistintamente de la orilla desde la que se mire, pues tal "decisión" ocurre bajo coacción, debido a presiones de tipo político, social y económico" (Brett \& Specht, 2004, p. 23).

En el contexto colombiano enmarcado en un "Conflicto Armado Interno" de más de 60 años entre el Estado, las guerrillas del Ejército de Liberación Nacional (ELN) y las Fuerzas Armadas RevolucionariasEjército del Pueblo (ex FARC-EP) y los Grupos Armados Organizados (GAO), los niños y adolescentes una vez hacen parte de las filas, ejecutan funciones que van desde las consideradas de "apoyo" hasta las ejercidas por los combatientes directos; $\mathrm{y}$, del mismo modo, se ven sometidos tanto a peligros constantes a su vida e integridad física y a todo tipo de actos que atentan contra su dignidad humana, como convertirse en esclavos sexuales y ejercer la prostitución, con el agregado de soportar tales circunstancias ya sea por miedo, por necesidad o por la imposibilidad misma de salir de la organización delincuencial. Los niños soldados son utilizados a menudo por las misiones más peligrosas, tales como la detección de minas o como escudos para repeler los ataques, ya que, en muchas ocasiones, son usados para formar la primera fila de combate.
Las conductas criminales de reclutar o alistar a niños o utilizarlos para participar activamente en las hostilidades se constituyen sin duda alguna como uno de los delitos más graves que afectan a la comunidad internacional. "Actualmente existe un importante marco normativo a nivel internacional que les brinda a los menores una protección especial y prohíbe su reclutamiento y vinculación a grupos armados" (Drumbl, 2012). En derecho internacional, hay que diferenciar entre la prohibición de reclutar o usar a niños soldados y la criminalización de esta conducta, que se cristalizó más tarde.

El reclutamiento y la utilización de niños, niñas y adolescentes por grupos armados ilegales en Colombia, sigue siendo una política interna, generalizada y sistemática; si bien se desconoce su naturaleza y magnitud exactas, se ha registrado un aumento de los casos, los grupos armados no estatales siguen teniendo un significativo número de NNA en sus filas y corresponde a una decisión consciente de los máximos responsables de estas "organizaciones". Conforme a lo anteriormente expuesto y lo consignado en el Derecho Internacional Humanitario ¿Por qué es posible utilizar NNA como combatientes y cuáles son las características que estos deben cumplir para hacer parte de las hostilidades?

\section{FUENTES DE LA PROHIBICIÓN INTERNACIONAL DE RECLUTAMIENTO DE MENORES DE 15 AÑOS COMO CRIMEN DE GUERRA}

Según la afirmación de Cryer, Friman, Robinson \& Wilmshurst (2007): "Un crimen de guerra es una seria violación de las leyes y costumbres aplicables a los conflictos armados (también conocidas como el Derecho Internacional Humanitario), que trae como consecuencia la responsabilidad individual criminal de perpetrador bajo el derecho internacional". En virtud a que el derecho de los crímenes de guerra está estrechamente ligado al DIH, se expondrán primero algunos conceptos esenciales de este y luego se discutirán los elementos 
comunes a todos los crímenes de guerra, para finalmente entrar en los tipos penales individuales.

La mayor diferencia que distingue los crímenes de lesa humanidad de los crímenes de guerra es que los últimos no exigen la comisión amplia o sistemática. Un sólo acto aislado puede constituir un crimen de guerra, independiente del marco dentro del cual ocurrió. El único requisito contextual es el nexo del crimen con el conflicto armado, lo que distingue el crimen de guerra de un crimen común. Sin embargo, la estructura de los tipos penales de los crímenes de guerra es más parecida al derecho penal ordinario que los tipos de lesa humanidad.

\subsection{Principios esenciales del Derecho Internacional Humanitario (DIH).}

El DIH es un derecho bien particular porque su objetivo es la regulación legal de la situación excepcional de conflicto armado. La complicación surge de la naturaleza extraordinaria de la guerra donde las reglas normales de la convivencia humana, como v.gr. las prohibiciones fundamentales de matar o destruir, se encuentran suspendidas o anuladas. A un combatiente no se le puede castigar por actos de guerra legalmente permitidos. Mientras los antiguos romanos decían "inter arma enim silent leges" (en la guerra, el derecho calla), la aspiración en tiempos modernos ha sido evitar un vacío legal en los conflictos armados e introducir progresivamente normas para humanizar (evitar el sufrimiento innecesario) la conducta en las hostilidades. (...) "Pero existe una tensión constante entre las exigencias humanitarias y las consideraciones militares, lo cual no siempre es fácil de resolver. La tendencia en el DIH de los últimos 100 años, ha sido claramente en la dirección de "humanizar el derecho humanitario", es decir, poner creciente énfasis en la protección de la vida humana en los conflictos armados" (Meron, 2000). Este desarrollo se manifiesta en las reglas más estrictas de conducta permisibles para las fuerzas armadas, en la expansión de la protección a clases adicionales de víctimas y en la aplicación del DIH a un creciente número de situaciones, inclusive el conflicto armado interno.

El DIH tradicionalmente ha sido dividido en dos cuerpos de derecho: (i) el derecho de Ginebra (enfocado en la protección de grupos que no participan activamente en las hostilidades) y (ii) el derecho de La Haya (sobre los métodos y armas permitidos en la guerra, con el fin de reducir el sufrimiento innecesario). Las Regulaciones de La Haya (1907) y los Convenios de Ginebra (1949) son las más importantes emanaciones de estas dos líneas del DIH. La inmensa mayoría de estas reglas aplica solamente en los conflictos internacionales (o sea con dos o más Estados participantes). Con la adopción de los dos Protocolos Adicionales a los Convenios de Ginebra (1977), que especifican reglas sobre la protección de no combatientes y la prohibición de ciertas prácticas y armas de combate, esta distinción se ha vuelto menos relevante.

Es importante subrayar que el DIH comienza a regir con el estallido de un conflicto armado, pero no se interesa por los orígenes o causas del conflicto. El argumento que alguna de las partes en el conflicto esté combatiendo por una causa justa o defendiendo algún bien colectivo superior (la democracia, la justicia social, etc.) no tiene ninguna influencia sobre la aplicación o interpretación del DIH en este conflicto. No se puede argumentar, v.gr., que en una guerra injusta, todos los actos de matar a combatientes fueron criminales y todos los ataques desproporcionados.

El derecho de los crímenes de guerra se fundamenta en el DIH, pero no toda violación del derecho humanitario constituye un crimen de guerra. Algunos tratados como los Convenios de Ginebra explícitamente criminalizan ciertas violaciones, las así llamadas infracciones graves (grave breaches). Otros crímenes de guerra se pueden encontrar en el derecho internacional consuetudinario; por ejemplo, el Tribunal Militar Internacional de Núremberg determinó que normas claves de las Regulaciones de la Haya (1907) eran 
parte del derecho consuetudinario y su violación constituía un crimen, aunque el texto de las Regulaciones no criminalizó explícitamente estas violaciones.

\subsection{Prohibición de reclutamiento}

Tanto en el Derecho Internacional Humanitario (DIH) como en el Derecho Internacional de los Derechos Humanos, y el Derecho Penal Internacional han sido consagradas disposiciones que prohíben el reclutamiento de niños tanto en los grupos armados irregulares como en la fuerza pública de los Estados. Mientras el DIH y el derecho de los derechos humanos se limitan a prohibir la conducta sin imponer sanción al perpetrador, el derecho penal internacional sí establece la responsabilidad individual criminal por realizarla.

Los niños y las niñas que se encuentran en medio de conflictos armados son protegidos por el Derecho Internacional Humanitario desde una doble perspectiva: (i) se les brinda resguardo en su calidad de menores civiles perjudicados por las hostilidades y (ii) como sujetos vinculados a ellas tanto en conflictos armados de carácter internacional como no internacional, concretándose esta protección como la prohibición del reclutamiento y la participación de niños en los conflictos armados.

Dentro de la normatividad constitutiva del DIH se encuentran:

\section{Cuatro convenios de Ginebra (1949)}

Ninguno de los cuatro convenios de Ginebra (I Convenio para aliviar la suerte que corren los heridos y los enfermos de las fuerzas armadas en campaña, II Convenio para aliviar la suerte que corren los heridos, los enfermos y los náufragos de las fuerzas armadas en el mar, III Convenio relativo al trato debido a los prisioneros de guerra, IV Convenio relativo a la protección debida a las personas civiles en tiempo de guerra) hace ninguna referencia al reclutamiento o uso de niños soldados. No obstante, la situación de los niños en un conflicto armado está cubierta por varios artículos del IV Convenio: el Artículo 14, relativo a las zonas de seguridad, indica que esas zonas pueden proteger en particular los niños menores de quince años. Los niños también son mencionados en el artículo 17, que prevé la evacuación de civiles de las zonas sitiadas. Artículo 23, que trata del libre paso para los envíos humanitarios destinados a las categorías más débiles de la población, se refiere explícitamente a los niños menores de quince años, entre los beneficiarios potenciales.

Artículo 24 del IV Convenio está completamente dedicado a los niños, con destaque para los niños menores de quince años que hayan quedado huérfanos o que estén separados de su familia a causa de la guerra, y a la identificación de los niños menores de doce años. El Artículo 38, que aplica a las personas protegidas en el territorio nacional de los beligerantes, incluye a los niños menores de quince años entre las personas que deben gozar de un trato preferencial. El Artículo 50 se ocupa de los niños en los territorios ocupados y de las instituciones dedicadas a su cuidado. Igualmente, en territorio ocupado, el Artículo 51 prohíbe que el poder ocupante obliga a los residentes menores de dieciocho años a trabajar, y el artículo 68 prohíbe pronunciar la pena de muerte contra personas menores de dieciocho años de edad. Esta última disposición, la cual no permite ninguna derogación, se ha adoptado también en el Pacto Internacional de 1966 sobre Derechos Civiles y Políticos (artículo 6, párrafo 5).

Aunque los Convenios de Ginebra no contienen una provisión explícita sobre el reclutamiento de menores, la prohibición de esta práctica está implícita en el común Artículo 3 de los Convenios, según el cual la población no combatiente será tratada con humanidad. Reclutar menores de edad pone su vida e integridad física en peligro inminente, ya que les quita su estatus de civiles protegidos y los convierte en objetivos militares legítimos. "Eso es una violación abierta y grave del principio de inmunidad de los no combatientes" (Gardam,1993) y de la prohibición de "atentar contra la vida y la 
integridad corporal" de personas protegidas (Común Art. 3, parra 1, letra a). En virtud del ámbito amplio de aplicación del común Artículo 3, esta prohibición es válida tanto en conflictos de carácter internacional como no internacional.

\section{Protocolo Adicional I a los Convenios de Ginebra relativo a la protección de las víctimas de los conflictos armados internacionales (1977)}

El Art. 77 trata de la protección de los niños en situaciones de conflictos armados. Su párrafo 1 reza: "[l]os niños serán objeto de un respeto especial y se les protegerá contra cualquier forma de asalto indecente." El párrafo 2 establece: "2. Las Partes en conflicto tomarán todas las medidas posibles para que los niños menores de quince años no participen directamente en las hostilidades, especialmente absteniéndose de reclutarlos para sus fuerzas armadas. Al reclutar personas de más de quince años, pero menores de dieciocho años, las Partes en conflicto procurarán alistar en primer lugar a los de más edad". Si es capturado un combatiente que tiene menos de quince años, "deberá seguir beneficiándose de la protección especial concedida por el presente artículo, sea o no un prisionero de guerra". (Art. 77, parra. 3). Se puede constatar que el Protocolo Adicional I no instaura una prohibición muy fuerte del reclutamiento ("tomaran todas las medidas posibles"), aunque hay que recordar que este instrumento aplica solamente a los conflictos internacionales ${ }^{1}$.

\section{Protocolo Adicional II a los Convenios de Ginebra relativo a la protección de}

1. El comentario de la Cruz Roja sobre el Protocolo Adicional I resalta que el CIRC había propuesta una formulación más exigente, pero no fue posible convencer los Estados de aceptar una obligación incondicional. Aunque la norma de abstenerse de reclutar niños menores de quince queda intacta, ya no se menciona una explícita obligación a rechazar su inscripción voluntaria. De hecho, de acuerdo con el Relator, el Comité III señaló que a veces, especialmente en los territorios ocupados y en las guerras de liberación nacional, no sería realista prohibir totalmente la participación voluntaria de los niños menores de quince años en los conflictos armados.

\section{las víctimas de los conflictos armados sin carácter internacional (1977)}

Según el Art. 4, párrafo 3, letra c): “3. Se proporcionarán a los niños los cuidados y la ayuda que necesiten y, en particular: (...) c) los niños menores de quince años no serán reclutados en las fuerzas o grupos armados y no se permitirá que participen en las hostilidades". Se nota aquí una interesante diferencia con el Protocolo Adicional I, en lo que la prohibición del reclutamiento de menores es más rigurosa en los conflictos de carácter no internacional ("no serán reclutados y no se permitirá que participen en las hostilidades"). La razón por esta divergencia yace en la historia de la redacción de los dos protocolos, porque fueron elaborados por dos comités diferentes de la Conferencia diplomática de 1977.

Bothe, Partsch \& Solf (2010) afirman que: "El Comité III (encargado del Protocolo Adicional I) decidió tomar una línea más permisiva frente al reclutamiento de menores, mientras el Comité I (encargado del Protocolo Adicional II) siguió las recomendaciones de la Cruz Roja y mantuvo una prohibición completa de la práctica" Sin embargo, Gary y Solis (2010) dicen que "ninguno de los dos protocolos establece la violación de estas provisiones como una infracción grave del DIH, que obligaría a los Estados partes a imponer sanciones penales a las personas que la hayan cometido, o dado orden de cometerla".

Por otro lado, en el marco de las normas del Derecho Internacional de los Derechos Humanos se encuentran las siguientes normas relacionadas con la protección de los menores de edad contra su reclutamiento o uso en las hostilidades.

La primera convención internacional que estipuló una prohibición de esta práctica fue la Convención sobre los derechos del niño (1989), cuyo Artículo 36 especifica: "Los Estados Partes protegerán al niño contra todas las demás formas de explotación que sean perjudiciales para cualquier aspecto de su bienestar". Así mismo, en el Artículo 38, párrafos 2-3 quedó establecido lo siguiente: 
"2. Los Estados Partes adoptarán todas las medidas posibles para asegurar que las personas que aún no hayan cumplido los 15 años de edad no participen directamente en las hostilidades. 3. Los Estados Partes se abstendrán de reclutar en las fuerzas armadas a las personas que no hayan cumplido los 15 años de edad. Si reclutan personas que hayan cumplido 15 años, pero que sean menores de 18, los Estados Partes procurarán dar prioridad a los de más edad". Esta convención de los derechos humanos es la más ampliamente ratificada del mundo y prohíbe tanto el reclutamiento como el uso de niños debajo de los 15 años en las hostilidades, reforzando las prohibiciones originando en el DIH" (Ang, 2005).

Al estipular esta prohibición del reclutamiento, la Convención es el único instrumento internacional de los derechos humanos que incorpora una provisión que pertenece al área del DIH que normalmente se trata de forma separada".

Sin embargo, estas normas no fueron consideradas como suficientes (especialmente en relación con el umbral de edad) por muchos activistas y estados. Liderado por el primer representante especial del Secretario General para la cuestión de los niños y los conflictos armados, el ugandés Olara Otunnu, se inició una campaña para aplicar presión sobre los gobiernos a adaptar un límite de edad de 18 años para los fines de reclutamiento. El resultado fue el Protocolo facultativo de la Convención sobre los derechos del niño relativo a la participación de niños en los conflictos armados (2000), cuyas provisiones reflejan el nuevo consenso sobre la edad. Según el Art. 1, "Los Estados Partes adoptarán todas las medidas posibles para que ningún miembro de sus fuerzas armadas menor de 18 años participe directamente en hostilidades". Además, el Art. 2 reza: "[l]os Estados Partes velarán por que no se reclute obligatoriamente en sus fuerzas armadas a ningún menor de 18 años". La única excepción permitido por el Protocolo (Art. 3, párrafo 3 ) es el alistamiento voluntario, con el consentimiento informado de los padres o guardianes del menor. Para este fin, Happold (2000) dice: "La edad mínima ha sido elevada de los 15 años. Los permitidos por la Convención a los 16 años. Cada Estado debe depositar una declaración vinculante sobre la edad de alistamiento voluntario permitido bajo su legislación nacional, y varios lo han hecho, con edades entre los 16 y 17 años".

El Protocolo es más restrictivo refiriéndose a los grupos armados irregulares y establece que: "1. Los grupos armados distintos de las fuerzas armadas de un Estado no deben en ninguna circunstancia reclutar o utilizar en hostilidades a menores de 18 años. 2. Los Estados Partes adoptarán todas las medidas posibles para impedir ese reclutamiento y utilización, con inclusión de la adopción de las medidas legales necesarias para prohibir y tipificar esas prácticas. 3. La aplicación del presente artículo no afectará la situación jurídica de ninguna de las partes en un conflicto armado".

De esta forma, el Protocolo facultativo introduce un tratamiento diferencial entre las fuerzas oficiales de un Estado que pueden bajo ciertas condiciones como la auténtica voluntariedad aceptar a menores entre los 15 y los 18 años y los grupos armados irregulares que no deben en ninguna circunstancia utilizar menores debajo de los 18 años. El Protocolo soló prevé la posibilidad de que sea evaluada la voluntariedad en los casos de reclutamiento de menores por parte del Estado, pues, en lo relativo a los demás grupos armados existe prohibición expresa que no admite excepción alguna de reclutar o utilizar menores de 18 años de edad en las hostilidades, lo que quiere decir que, aunque el joven manifieste su voluntad de incorporarse en el grupo armado, el alistamiento de este está prohibido.

Otros instrumentos internacionales
de los derechos humanos también
tratan del reclutamiento de menores. Se
puede mencionar el Convenio 182 de la
Organización Internacional de Trabajo (OIT)
sobre la prohibición de las peores formas de
trabajo infantil y la acción inmediata para su
eliminación (1999). Este tratado multilateral


define el término niño como: "toda persona menor de 18 años" (Art. 2). Entre las "peores formas de trabajo infantil", el Convenio nombra "todas las formas de esclavitud o las prácticas análogas a la esclavitud, como la venta y el tráfico de niños, la servidumbre por deudas y la condición de siervo, y el trabajo forzoso $\mathrm{u}$ obligatorio, incluido el reclutamiento forzoso u obligatorio de niños para utilizarlos en conflictos armados" (Art. 3, parra. 1, letra a). Según lo afirmado por la OIT (Convenio, 1999): "Los Estados partes se comprometen a "adoptar medidas inmediatas y eficaces para conseguir la prohibición y la eliminación de las peores formas de trabajo infantil con carácter de urgencia". La recomendación 190 de la OIT, que acompaña al Convenio 182, recomienda la criminalización del reclutamiento forzado de menores.

En el contexto regional africano, especialmente afectado por el fenómeno del reclutamiento ilícito. Honwana (2007) expresa: “(...) los Estados miembros de la Organización de Unidad Africana adoptaron la Carta Africana de los derechos y del bienestar del niño (1990), que entró en fuerza en 1999". En su Art. 22, párrafo 2, la Carta establece que "Los Estados Parte en la presente Carta adoptarán todas las medidas necesarias para garantizar que ningún niño tome parte directamente en las hostilidades y, en especial, se abstendrán de reclutar a algún niño". Importante en este contexto es que la Carta entiende por niño todo ser humano menor de dieciocho años (Art. 2).

Todas estas normas del derecho internacional, tanto del DIH como de los derechos humanos, establecieron una prohibición general del reclutamiento y del uso de niños soldados, las cuales, según el estudio detallado de la Cruz Roja (International Committee of the Red Cross, 2006) “(...) en el año 2005 han adquirido la naturaleza de derecho consuetudinario internacional (Reglas 136 y 137)". Eso quiere decir que estas prohibiciones tienen validez para todos los Estados, independientemente si han ratificado o no las convenciones que acabamos de mencionar. Como fundamentos para la regla del derecho consuetudinario, existe una práctica amplia de los Estados de prohibir este comportamiento en sus manuales militares y legislación interna, no hay práctica oficial contraria y las ocurrencias de reclutamiento que salieron a la luz en varios conflictos en el mundo generalmente fueron públicamente condenados tanto por Estados como por organizaciones internacionales.

Los Elementos de los Crímenes para el Estatuto de la Corte Penal Internacional (2002) fueron elaborados para darles una ayuda interpretativa sobre los crímenes especificados en los artículos 6, 7 y 8 del Estatuto a los jueces de la Corte. Para una acusación penal internacional por el crimen de reclutamiento de menores, todos los elementos típicos enumerados deben estar presentes:

1. Que el autor haya reclutado o alistado a una o más personas en fuerzas armadas o grupos o las haya utilizado para participar activamente en las hostilidades.

2. Que esa o esas personas hayan sido menores de 15 años.

3. Que el autor haya sabido o debiera haber sabido que se trataba de menores de 15 años.

4. Que la conducta haya tenido lugar en el contexto de un conflicto armado (de carácter internacional o no internacional) y haya estado relacionada con él.

5. Que el autor haya sido consciente de circunstancias de hecho que establecían la existencia de un conflicto armado".

El crimen de guerra de reclutamiento de menores tipificado en el Estatuto de Roma es inusual en dos aspectos: primero, pretende proteger los niños frente a sus propias autoridades, lo que se diferencia de la orientación general del DIH, que protege, en este caso, a los civiles de las violaciones cometidas por el otro bando en un conflicto armado. En este aspecto, la norma refleja más el derecho de los derechos humanos que el propio DIH. Segundo, como el alistamiento y reclutamiento generalmente ocurren sin ningún nexo con un conflicto armado. Para 
Cottier (2010) "este crimen puede cometerse también en tiempos de paz (no obstante, los elementos antes citados sobre el nexo al conflicto armado, que no aparecen en el Estatuto mismo)".

Los estatutos de los Tribuales Internacionales Penales para ex Yugoslavia y Ruanda no contienen ninguna referencia a este crimen, ya que no se tenía noticia de la ocurrencia de reclutamiento de menores en estos conflictos. Sin embargo, esta conducta se encuentra criminalizada en el Estatuto para la Corte Especial de Sierra Leona, establecida en 2002 para juzgar a los máximos responsables por los crímenes masivos cometidos en este país. El artículo 4 del Estatuto establece la competencia de la Corte Especial para perseguir a las personas que cometieron las siguientes violaciones serias del Derecho Internacional Humanitario: "c) [r]eclutar o alistar a niños menores de 15 años en las fuerzas armadas o grupos o utilizarlos para participar activamente en las hostilidades".

Como hemos visto, la criminalización del reclutamiento y uso de menores para fines del conflicto armado es de fecha relativamente reciente y antes de la codificación del crimen, no se habían enjuiciado ningunos casos de esta conducta. Cuando los tribunales penales internacionales comenzaron a investigar a los responsables, se enfrentaron con diferentes problemas de definición y aplicación. Sus decisiones en casos concretos se volvieron entonces cruciales para la interpretación e implementación de estas normas.

\section{EL RECLUTAMIENTO DE NIÑOS, NIÑAS Y ADOLESCENTES -CASO COLOMBIA-}

En Colombia esta conducta que reviste enorme gravedad. Está absolutamente prohibido, ya que, expresamente desde la entrada en vigencia de la Ley 418 de 1997 (art. 14) se adicionó al haber penal (art. 162 C.P.), el crimen de reclutamiento ilícito, amén del cual se hizo eco de una prohibición que viene dada desde el ámbito internacional. Esta norma prohíbe la utilización de niños con ocasión de conflicto armado bien sea directa o indirectamente en acciones armadas, inclusive cuando sean "voluntarias", porque los menores de edad no poseen la capacidad para dar un consentimiento de esa naturaleza.

Por ende, el crimen de conscripción, reclutamiento o uso de niños, niñas $y$ adolescentes para participar activamente en las hostilidades se encuadra dentro de la lista de conductas punibles que están codificadas a nivel internacional, bien sea como delito de lesa humanidad, o como crimen de guerra, y a la vez también aparece dentro del estatuto punitivo colombiano, de manera directa y además en virtud de la integración de convenios y estatutos internacionales.

Para el caso de Colombia y su lucha de guerrillas en contra del Estado y en el contexto del conflicto armado ha traído violaciones, esclavitud sexual, prostitución forzada, embarazo forzado, esterilización forzada, crímenes propios de lesa humanidad que son cometidos en un ataque generalizado o sistemático contra una población civil. Los niños, niñas y adolescentes (NNA) hacen parte de la población más vulnerable a nivel mundial; en la historia de la humanidad han sido víctimas de ataques y guerras cuyas consecuencias han dejado huellas imborrables en sus vidas.

$\mathrm{Si}$ bien es cierto que los menores son objeto de protección por parte de la comunidad internacional y de una u otra forma se ha convertido en una obligación para los Estados proveerse de mecanismos que garanticen su dignidad, vida, salud, familia, entre otros derechos; en el conflicto interno colombiano se ha visto un aumento alarmante de NNA en las filas de los grupos armados ilegales que son vinculados $y$ utilizados para diseño y fabricación de minas antipersonales, explosivos, servidumbre sexual, trabajos forzosos y en una nueva forma de esclavitud. En su mayoría estos NNA terminaron siendo analfabetas funcionales que no superan los 15 años de edad.

Serán protegidos contra toda forma de abandono, violencia física o moral, secuestro, 
venta, abuso sexual, explotación laboral o económica y trabajos riesgosos. Gozarán también de los demás derechos consagrados en la Constitución, en las leyes y en los tratados internacionales ratificados por Colombia" (Constitución Política, Articulo $\left.44^{\circ}, 1991\right)$.

Si bien en Colombia el reclutamiento de NNA es ilegal y está reglamentado por la LEY 48 DE 1993, las Normas rectoras indican en el artículo 10 del capítulo 1 que: Todo varón colombiano está obligado a definir su situación militar a partir de la fecha en que cumpla su mayoría de edad, a excepción de los estudiantes de bachillerato, quienes definirán cuando obtengan su título de bachiller. La obligación militar de los colombianos termina el día en que cumplan los cincuenta (50) años de edad (Colombia, Ley 48 de 1993 capítulo I).

Los NNA que son víctimas del reclutamiento ilícito por parte de los grupos armados ilegales están amparados bajo la Ley 1448 del 2011, donde en su artículo 190 dicta:

Todos los niños, niñas y adolescentes víctimas del reclutamiento, tendrán derecho a la reparación integral en los términos de la presente ley. Los niños, niñas y adolescentes víctimas del delito de reclutamiento ilícito podrán reclamar la reparación del daño, de acuerdo con la prescripción del delito consagrada en el artículo 83 del Código Penal.

Según la UNICEF -en su protocolo facultativo de la convención sobre los Derechos del Niño- relativo a la Participación de Niños en los Conflictos Armados, establece los 18 años como edad mínima para el reclutamiento obligatorio por parte de los gobiernos, la participación directa en las hostilidades o el reclutamiento por grupos armados. Los Estados pueden aceptar voluntarios desde los 16 años, pero deben depositar una declaración vinculante al ratificar el presente Protocolo o adherirse al mismo, estableciendo la edad mínima de reclutamiento voluntario y exponiendo ciertas salvaguardias. (UNICEF, 2004).

Desde la época colonial se ha venido incluyendo a los NNA en los grupos armados que hacen presencia, fue entonces cuando en los años 40 la Corte Penal Internacional se pronuncia señalando el reclutamiento de niños en el listado de "Crímenes de Guerra".

Por medio de la Convención sobre los Derechos de los Niños en 1985 se establece la edad de los 15 años como límite mínimo para el reclutamiento. En la actualidad del conflicto interno colombiano, los grupos insurgentes reclutan despiadadamente mano de obra infantil y NNA para propósitos de su accionar.

(...) El reclutamiento no puede calificarse como un acto voluntario. Aún en los casos en que se ve facilitado por la vulnerabilidad social y económica de los afectados, de ninguna manera tendría lugar sin la existencia de un conflicto armado, cuya violencia produce dinámicas que alienan todos los derechos y las libertades de las comunidades sometidas y arrastra consigo, especialmente, a los más vulnerables" (Springer, 2012).

Una explicación ante la presencia de NNA indígenas en las filas de los grupos armados ilegales se da en la tasa de rendimiento y la tasa de deserción, estos NNA indígenas son los que mejor resisten las difíciles condiciones del reclutamiento y los que menos desertan o abandonan las filas. Dado sus circunstancias socioeconómicas y culturales, así como la ubicación de sus territorios ancestrales, coinciden con la localización de corredores estratégicos y zonas de explotación de recursos. En zonas específicas Colombia, estos grupos han trazado "fronteras invisibles" y han declarado barrios y comunas como "zonas de guerra", donde los NNA deben cooperar con ellos para sobrevivir.

Las guerrillas y las bacrim colombianas reclutan NNA sistemáticamente para todos sus frentes, unidades $y$ organizaciones no solo como combatientes. La mano de 
obra infantil y adolescente es fundamental en el cumplimiento de cada objetivo y de cada actividad estratégica de estos grupos ilegales, históricamente se han encargado de reclutar NNA, con técnicas de regalos y "donaciones" en comida y dinero, esto le permite a los NNA suplir necesidades básicas insatisfechas y por otra parte contribuir con los gastos del diario en sus casas. Estos grupos al margen de la ley realizan labores de inteligencia en colegios y escuelas rurales permitiendo "perfilar" aquellos NNA en situación de vulnerabilidad y que presenten problemas familiares y violencia familiar, se presentan como el "ICBF Alternativo" ante la falta de presencia del estado colombiano y la falta de oportunidades laborales; Otorgando beneficios económicos por la prestación de sus servicios como lo son llevar mensajes, comprar víveres, realizar labores de inteligencia y hasta la prestación de servicios sexuales. (...) El proceso del reclutamiento comienza por involucrar al niño en tareas como mandados, remesas y demás que no despierten mayor complicación y alertas con la fuerza pública a cambio les dan un dinero para golosinas o para "la gaseosa", a medida que el niño crece se va involucrando cada vez más en tareas con mayor responsabilidad inteligencia, fabricación e instalación de minas, cobro de extorsiones y vacunas hasta llegar a portar un uniforme y fusil (Springer, 2012).

Existe amplia evidencia de que las disidencias de las FARC-EP y los GAO reclutan menores de 15 años según un patrón consistente y sostenido con una amplia dispersión territorial. La función del reclutador es un rango especializado de importancia estratégica, lo que a su vez constituye evidencia de un plan o una política organizacional. Actualmente según Springer el fenómeno del reclutamiento de NNA en Colombia se ha visto propagado en edades más cortas (antes de los 14 años de edad) ya que por esta condición si son atrapados por la fuerza pública están amparados por el gobierno y deben de inmediato dejarse en libertad o en manos del ICBF, no podrán ser interrogados, sometidos y utilizados para dar información del adversario.
Según el informe de Naciones Unidas de 2012 del 100\% de niños, niñas y adolescentes en las filas de estos grupos armados ilegales el 30\% provienen de departamentos donde existe poca presencia del Estado y son apetecidos por estos grupos ilegales ya que cumplen ciertos requisitos propios de su condición para sortear y evadir toda responsabilidad legal y jurídica, NNA que por su raza son más fuertes para afrontar retos ambientales, conocedores de la región, menores de 14 años ya que en caso de ser capturados son inmunes gracias a su condición de cualquier clase de interrogatorio por parte de las fuerzas militares y/o armadas (ACNUR, 2012).

Suárez (2009) afirma que "Las conductas de reclutar o alistar niños o de utilizarlos para participar activamente en las hostilidades constituyen algunos de los delitos más graves que afectan a la comunidad internacional". Como reflejo de las normas internacionales, la conducta está también prohibida en Colombia. Con la entrada en vigencia de la Ley 418 de 1997 se tipificó el crimen de reclutamiento ilícito (art. 162 C.P.). Esta norma prohíbe la utilización de niños con ocasión de conflicto armado, bien sea directa o indirectamente en acciones armadas, inclusive cuando esta se produzca con la aceptación del menor. Demostrando que se trata de un fenómeno masivo y amplio, convirtiéndose en uno de los crímenes que más frecuente y sistemáticamente ha ejecutado los miembros de las disidencias de la ex guerrilla de las FARC y los GAO, por encima de otros de similar gravedad.

Para concluir, el reclutamiento de NNA es una política de las organizaciones al margen de la ley, que responde a estrategias concretas y decisiones tomadas al máximo nivel, donde existe responsabilidad individual directa de aquellos individuos que reclutan o alistan NNA, o los utilizan para participar en las hostilidades. Este grupo de personas incluye los reclutadores, y los comandantes de unidades como escuadras o frentes también a los que aprobaron y ordenaron implementar esta política, los que proporcionaron soporte y apoyo y los que hicieron cualquier otra contribución 
material al plan. En el caso concreto del reclutamiento, esto incluye prácticamente todos los cuadros de la organización guerrillera hasta la cúpula máxima porque el reclutamiento de combatientes (incluyendo los menores de edad) es una de las estrategias de mantenimiento más críticas para el mantenimiento de su actividad.

La responsabilidad de los máximos jefes de la ex guerrilla de las FARC y los GAO, cuyas órdenes se cumplen prácticamente sin contratiempos al interior de la organización, tampoco se limita a dar una instrucción a sus subalternos, ni se restringe a poner en marcha el aparato organizado de poder. Ellos constituyen la esencia misma del aparato organizado de poder. Revisados los documentos rectores de las FARC-EP, no cabe duda de la responsabilidad del Estado Mayor Central y su Secretariado en todas las actuaciones delictivas del grupo desde su conformación, por cuanto, ejerciendo como órgano de dirección, v.gr. aducen que, (i) ha existido una sola dirección que resuelve los problemas políticos, militares, organizativos, etc., esa dirección es en la actualidad el E.M. [Estado Mayor]; (ii) sin la unidad de la dirección esto no sería posible; (iii) todos los grupos, guerrillas destacamentos, comisiones, mantendrán comunicación directa y permanente con el E.M. a través de su órgano ejecutivo o su secretariado, para que le informen el desarrollo de sus tareas; (iv) La subordinación a las órdenes y determinaciones de los órganos superiores y del Comandante en Jefe, es una norma de obligatorio cumplimiento para todos los combatientes; (v) las FARC-EP están a disposición y bajo el mando directo del Estado Mayor Central.

\section{CONCLUSIONES}

Tanto en el Derecho Internacional Humanitario (DIH) como en el Derecho Internacional de los Derechos Humanos y el Derecho Penal Internacional han sido consagradas disposiciones que prohíben el reclutamiento de niños tanto en los grupos armados irregulares como en la fuerza pública de los Estados. Mientras el DIH y el derecho de los derechos humanos se limitan a prohibir la conducta sin imponer sanción al perpetrador, el derecho penal internacional también establece la responsabilidad individual criminal por realizarla.

Los niños y las niñas que se encuentran en medio de conflictos armados son protegidos por el Derecho Internacional Humanitario desde una doble perspectiva: (i) se les brinda resguardo en su calidad de menores civiles perjudicados por las hostilidades y (ii) como sujetos vinculados a ellas tanto en conflictos armados de carácter internacional como no internacional, concretándose está protección como la prohibición del reclutamiento y la participación de niños en los conflictos armados.

El proceso del reclutamiento de NNA por las bacrim y GAO comienza por involucrar al niño en tareas como mandados, remesas y demás que no despierten mayor complicación y alertas con la fuerza pública a cambio les dan un dinero para golosinas o para "la gaseosa", a medida que el niño crece se va involucrando cada vez más en tareas con mayor responsabilidad inteligencia, fabricación e instalación de minas, cobro de extorsiones y vacunas hasta llegar a portar un uniforme y fusil.

Lo anterior refleja que el conflicto armado no se trata únicamente de la situación fáctica del combate, sino que además comprende multiplicidad de acciones que tienen lugar dentro de un grupo organizado. Para imputar la conducta de reclutar, alistar o usar a menores de los 15 años para fines del conflicto armado, existe entonces la opción de clasificar la conducta como crimen de guerra, o -alternativamente- como un crimen de lesa humanidad, siempre y cuando los elementos generales de este tipo penal están dados. Los próximos dos apartes van a analizar estos dos escenarios. 


\section{REFERENCIAS BIBLIOGRÁFICAS}

» ACNUR. (2012). Informe anual sobre trata de personas. Recuperado de: http:// www.acnur.org/t3/fileadmin/scripts/doc.php?file=biblioteca/pdf/5147

» Alerta vida ONG, (2012). Informe de niñez. Explotación infantil. Recuperado: http://alertavidaong.es.tl/Informe-Ni\%F1ez-.htm

» ARC Acciones por los Derechos del Niño. (2004). Niños, niñas y adolescentes vinculados al conflicto. Recuperado de: http://www.arc-online.org/translations/ spanish/childsoldierssp.doc

» A.R.C. (2011). Taller: Niños vinculados al conflicto. Recuperado de: https:// campusvirtual.univalle.edu.co/moodle/pluginfile.php/466044/mod_resource/ content/1/Ni\%C3\%B1os\%20vinculados\%20al\%20conflicto\%20taller.pdf

Colombia, (2001). Acto legislativo. Art.93 Corte Penal

» Constitución Política de Colombia. (1991).

» Comisión Colombiana de Juristas. (2010). Informe alterno al informe del Estado colombiano sobre el cumplimiento del Protocolo Facultativo Relativo a la Participación de Niños en los Conflictos Armados. Recuperado: http://www.coalico. org/archivo/IA10_EspIng.pdf

» CONPES, (2010). Política de prevención del reclutamiento y utilización de niños, niñas, adolescentes por parte de los grupos armados organizados al margen de la ley y de los grupos delictivos organizados. Recuperado de: https://www.dnp. gov.co/LinkClick.aspx?fileticket=PbBQ7BezSyo\%3D\&tabid=304

» CONPES, (2010). Prevenir el reclutamiento y utilización de niños, niñas y adolescentes es asunto de todos, versión resumida documento CONPES 3673. Recuperado de: http://www.vicepresidencia.gov.co/Iniciativas/Documents/Conpes3673-cartilla.pdf

» Convención de los Derechos Humanos, (1989). Protocolo facultativo de la Convención sobre los Derechos del Niño relativo a la venta de niños, la prostitución infantil y la utilización de niños en la pornografía, Artículo $2^{\circ} \mathrm{b}$.

» Convención de los Derechos Humanos, (1989). Protocolo facultativo de la Convención sobre los Derechos del Niño relativo a la venta de niños, la prostitución infantil y la utilización de niños en la pornografía, Artículo $2^{\circ}$ a.

» Cottier, M. (2010). "Art. 8 (xxvi) Participation of children in hostilities", op. cit., p. 470.

» Estatuto de Roma de la Corte Penal Internacional, (2002). El texto del Estatuto de Roma que se distribuyó como documento A/CONF.183/9, de 17 de julio de 1998. Recuperado de: http://www.un.org/spanish/law/icc/statute/spanish/ rome_statute(s).pdf

» Happold, M. (2000). "The Optional Protocol to the Convention on the Rights of the Child on the Involvement of Children in Armed Conflict." Yearb. Int'l Hum. L., Vol. 3, pp. 226-244 en p. 238.

» Honwana, A. (2007).Child Soldiers in Africa, Philadelphia: University of Pennsylvania Press 2006; Ishmael Beah, A Long Way Gone: Memoirs of a Boy Soldier. New York: Farrar, Straus \& Giroux. 
» Human Rights Watch. (2006). "Aprenderás a no llorar: niños combatientes en Colombia", Panorama sobre la Trata de Personas, Desafíos y respuestas: Colombia, República Dominicana y Estados Unidos.

» International Committee of the Red Cross, Customary International Humanitarian Law, Vol. 1: Rules. Cambridge: ICRC \& Cambridge University Press 2006, pp. 482-488.

» Instituto Colombiano de Bienestar Familiar. (2012). Observatorio del bienestar de la niñez, protegiendo a la niñez de la violencia sexual, boletín 2.

» Jóvenes constructores de política, (2012). Recomendaciones para la implementación de políticas de juventud. Recuperado: http://www.oim.org.co/publicaciones-oim/ninez-desvinculada.html

» La Guía. (2007). Psicología. La Sobreprotección. Recuperado de: http://psicologia.laguia2000.com/general/la-sobreproteccion

» Leiden, Ch. (2005). Martinus Nijhoff Publishers, p. 3.

» Niños 'made in Colombia'. (2012). Programa Séptimo Día. Recuperado de: http://www.noticiascaracol.com/informativos/septimodia/video-261949-ninosmade-in-colombia

» OIT. Convenio 182 sobre la prohibición de las peores formas de trabajo infantil y la acción inmediata para su eliminación, Ginebra, Conferencia Internacional de Trabajo, 87a reunión, junio de 1999, citada según http://www.ilo.org/public/spanish/standards/relm/ilc/ilc87/com-chic.htm

» Organización de Estados Americanos. (2007). Secretaría General. Octavo informe trimestral del Secretario General al Consejo Permanente sobre la Misión de Apoyo al Proceso de Paz en Colombia (MAPP/OEA). Recuperado: www.mapp-oea. org

» Observatorio del Bienestar de la Niñez. (2012). Vulnerabilidad, reclutamiento y utilización de niños, niñas y adolescentes por grupos armados organizados al margen de la ley. No 3. Recuperado de: http://www.icbf.gov.co/portal/page/portal/ PortalICBF/Bienestar/Programas\%20y\%20 Estrat\%C3\%A9gias/ObservatorioBienestar/Boletines/OBSERVATORIONINEZ_N3.pdf

» Palomo, G. (2009). Kindersoldaten und Völkerstrafrecht: die Strafbarkeit der Rekrutierung und Verwendung von Kindersoldaten nach Völkerrecht, Berlin: BWV Verlag.

» Rutas prevención. (2013). Prevención del reclutamiento y utilización de niños, niñas y adolescentes por grupos organizados al margen de la ley. Recuperado de: http://www.mineducacion.gov.co/cvn/1665/articles-326419_archivo_pdf.pdf

» Sayago. (2011). Desplazamiento forzoso en Colombia. Expulsión y Movilidad, dos dinámicas que interactúan. Bogotá: Universidad Nacional de Colombia. Recuperado de: http://www.bdigital.unal.edu.co/5901/1/tesis_sayago_Agosto_21.pdf

» Springer, N. (2012). Como corderos entre lobos.

» Tierra de hombres. (2010). Tdh derecho a la justicia menor y tráfico. Ayuda a la infancia. Recuperado de: http://www.slideshare.net/Tdhinfancia/tdh-derecho-ala-justicia-menores-y-trfico

» UNICEF. (2011). Protección infantil contra la violencia, la explotación y el abuso. Recuperado de: http://www.unicef.org/spanish/protection/index.html 